\title{
PROPUESTA DE UN MODELO EXPERIMENTAL DE ENTERITIS AGUDA INDUCIDA POR INDOMETACINA EN RATAS ALBINAS
}

\author{
Dunia Ramos A. ${ }^{1}$, Pedro Angulo H. ${ }^{2}$, Alfonso Chavera C. ${ }^{3}$ y Milder Ayón S. ${ }^{4}$
}

\section{Abstract}

Fifteen Holtzman male rats weighing 250 to $275 \mathrm{~g}$ were distributed in four groups. Group 1 was subcutaneously injected with $5 \% \mathrm{NaHCO} 3(n=20)$. Groups 2,3 and 4 received $15 \mathrm{mg} / \mathrm{kg}$ of indomethacin subcutaneously ( $\mathrm{n}=10 \mathrm{rats} /$ group). Macroscopic and microscopic evaluation of small intestine (jejunum-ileum) were carried out at first, second and third day after drug administration. Intestinal injury were observed along the mesenteric side of the middle and distal jejunum. Macroscopic lesions consisted of bowel thickening and dilatation, absence of the mucosa, hyperemia and multiple longitudinal and round ulcers. These lesions were observed at $24 \mathrm{~h}$ after drug injection and were present by $72 \mathrm{~h}$. There were no statistical differences $(\mathrm{p}>0.05)$ between groups 2, 3 and 4, relating to gross lesions. Microscopically, lesions were characterized by erosion of the mucosa, fibrinous and bacterial infiltration, neutrophilic and lymphocytic infiltration, necrosis of the mucosa and the muscularis, bowel perforations and fibroblastic proliferation. Lymphocytes were present at first day (primary cellular indicator of inflammation) and neutrophils were present at second day (cellular indicator of persistence and severity). Microscopic lesions were most evident by $24 \mathrm{~h}$ after drug injection.

Key words: indomethacin, rats, acute bowel inflammation

\section{Resumen}

Se reprodujo un modelo experimental de enteritis aguda con una dosis subletal de indometacina en ratas albinas para caracterizar las lesiones macro y microscópicas en el yeyuno-íleon. Se utilizaron 50 ratas machos Holtzman, con un peso de 250-275 g distribuidas en 4 lotes. El lote 1 (control, n=20) recibió una inyección subcutánea de $\mathrm{NaHCO} 3$ al $5 \%$ y a los lotes 2,3 y 4 ( $\mathrm{n}=10$ ratas/lote) se les aplicó indometacina $(15 \mathrm{mg} / \mathrm{kg}$ de peso vivo), vía subcutánea. La evaluación macro y microscópica del intestino delgado (yeyunoíleon) se hizo el primer, segundo y tercer día de inyectada la droga. Las lesiones intestinales se ubicaron en el lado mesentérico del yeyuno medio y distal. Macroscópicamente se observó engrosamiento y dilatación de la pared intestinal, pérdida de la mucosa, hiperemia y múltiples úlceras lineales y circulares, que fueron evidentes dentro de las primeras 24 horas de inyectada la indometacina, manteniéndose hasta las 72 horas. No se encontraron diferencias estadísticas con relación a lesiones microscópicas $(\mathrm{p}>0.05)$ entre los lotes 2, 3 y 4. Los hallazgos microscópicos estuvieron caracterizados por erosión de la mucosa, presencia de fibrina y bacterias, infiltrado neutrofílico y linfocitario, necrosis de la mucosa y la muscular, perforaciones intestinales y proliferación de fibroblastos. Los linfocitos

\footnotetext{
${ }^{1}$ Práctica privada

${ }^{2}$ Laboratorio de Farmacología y Toxicología, FMV-UNMSM.E-mail: panguloh@vet.unmsm.edu.pe

${ }^{3}$ Laboratorio de Histo-Patología Animal, FMV-UNMSM

${ }^{4}$ Laboratorio de Fisiología, FMV-UNMSM
} 
se hicieron presentes desde el primer día (indicador celular inicial de la inflamación) y los neutrófilos desde del segundo día (indicador de severidad y persistencia). Microscópicamente, las lesiones inflamatorias más marcadas ocurrieron al segundo día de aplicada la indometacina.

Palabras clave : indometacina, ratas, inflamación intestinal aguda

\section{INTRODUCCIÓN}

Las enfermedades entéricas son frecuentes y muy perjudiciales en el crecimiento y desarrollo de muchas especies y de gran impacto en la salud y producción animal.

La indometacina es una droga que pertenece al grupo de los antiinflamatorios no esteroideos (AINES), con propiedades antiinflamatorias, analgésicas y antipiréticas bastante potentes, aunque su toxicidad ha lim itadb su uso (Goodnan et al., 1991). En humanos, la administración crónica de indometacina produce inflamación gastroentérica y en animales experimentales la administración aguda reproduce el mismo cuadro (Yamada et al., 1993).

Se ha demostrado que una dosis subletal de indometacina induce inflamación aguda limitada al intestino medio de ratas, llegando a su máxima expresión al tercer día; observándose ulceración de la mucosa, diarrea e infiltración de granulocitos y monocitos (Yamada et al., 1993). Reuter et al. (1997) sugieren que la recirculación enterohepática de la indometacina es de capital importancia para producir daño en el intestino delgado, donde el número elevado de bacterias entéricas probablemente amplifican el daño inicial de la indometacina. Así mismo, la supresión sistémica de la síntesis de prostaglandinas no sería un componente crítico del daño intestinal.

En vista de la gran repercusión económica de los cuadros entéricos en diversas especies de animales domésticos, es necesario su estudio para lo cual se requiere del acondicionamiento de modelos experimentales animales. El presente trabajo tiene como objetivo proponer un modelo experimental animal de enteritis aguda con una dosis subletal única de indometacina en ratas albinas, bajo las condiciones no controladas del laboratorio, caracterizando el daño según los hallazgos macro y microscópicos. Este modelo experimental de enteritis aguda permitirá realizar y entender diversos estudios relacionados con este campo.

\section{Materiales y Métodos}

\section{Lugar de estudio}

El presente trabajo se realizó en el Laboratorio de Farmacología, Toxicología y Terapéutica y en el Laboratorio de HistoPatología de la Facultad de Medicina Veterinaria, Universidad Nacional Mayor de San Marcos, durante los meses de mayo y junio del 2001.

\section{Animales}

Se emplearon 50 ratas albinas macho de la raza Holtzman de aproximadamente 4 meses de edad, con un peso entre 250 y 275 g, provenientes del bioterio de la Universidad Nacional Agraria La Molina. Las ratas fueron distribuidas en 4 lotes de la siguiente manera:

- Lote 1: conformado por 20 ratas (control) a las que se les inyectó bicarbonato de sodio al 5\% vía subcutánea a nivel del dorso $(200 \mathrm{mg} / \mathrm{kg}$ p.v.)

- Lotes 2, 3 y 4: cada lote conformado por 10 ratas, las que recibieron una inyec- 
ción subcutánea de indometacina $(0.75 \%$, disuelto en bicarbonato de sodio al 5\%) en dosis de $15 \mathrm{mg} / \mathrm{kg}$ de peso vivo. Los lotes fueron sacrificados al primer, segundo y tercer día, respectivamente, de iniciado el experimento.

\section{Evaluación del daño intestinal}

Se evaluaron las lesiones post mortem del intestino delgado (yeyuno-íleon). A nivel microscópico se utilizó la escala propuesta por Yamada et al. (1993), que considera seis grados de lesión:

- Grado 0: no ocurren cambios en la mucosa ni en la serosa.

- Grado 1: hiperemia y/o sangrado petequial.

- Grado 2: única erosión o ulceración en la mucosa.

- Grado 3: única erosión o ulceración en la mucosa con hiperemia y lesiones adhesivas hemorrágicas en la serosa y el mesenterio.

- Grado 4: múltiples erosiones o ulceraciones, en menos de $10 \mathrm{~cm}$ de extensión.

- Grado 5: múltiples erosiones o ulceraciones, en más de $10 \mathrm{~cm}$ de extensión.

A nivel microscópico se evaluaron las lesiones inflamatorias utilizando la clasificación de Slauson y Cooper (1990), que considera tres grados de lesión:

- Grado leve: incluye escasa destrucción de tejido, escasas evidencias de daño vascular (hiperemia y edema) y poca exudación.

- Grado moderado: la reacción usualmente comprende una parte de tejido dañado y hallazgos visibles de reacción inflamatoria a la injuria, manifestada por la acumulación de leucocitos y fenómenos vasculares.

- Grado severo: comprende la extensión de la reacción moderada, en la cual se observa considerables daños del tejido en una gran extensión, así como abundante exudación.

\section{Análisis estadístico}

Para hallar la diferencia entre los lotes 2, 3 y 4 se empleó la prueba de Kruskall Wallis, y para calcular la relación entre los días transcurridos y el grado de lesión se utilizó la correlación de Spearman.

\section{Resultados}

No se encontraron lesiones en los animales del grupo control. Las lesiones intestinales en los animales tratados se ubicaron en el lado mesentérico del yeyuno medio y distal y estuvieron caracterizadas por el engrosamiento y dilatación de la pared intestinal, pérdida de la mucosa, hiperemia y presencia de múltiples úlceras lineales y circulares; lesiones que fueron evidentes dentro de las primeras 24 horas de inyectada la indometacina, y se mantuvieron hasta las 48 y 72 horas (Fig. 1, Cuadro 1).

Los hallazgos microscópicos observados fueron: erosión de la mucosa, corion expuesto y presencia de fibrina (Fig. 2) durante los tres días de evaluación. Las bacterias se presentaron en grado leve el primer día y en grado moderado y severo, el segundo y tercer día. Los neutrófilos estuvieron presentes a partir del segundo día y los linfocitos desde el primer día.

La necrosis de la mucosa, submucosa, muscular y serosa fue un hallazgo importante y varió con el transcurrir de los días. La necrosis abarcó la mucosa y la muscular en grado leve el primer día, en tanto que el segundo y tercer día comprendió desde la mucosa hasta la serosa en grado moderado a severo. Paralelamente, se observó la presencia de fibroblastos con neoformación de vasos (Fig. 2). Los cambios vasculares intestinales (arterias, venas, y microvasos) se observaron desde el primer día y se mantuvieron hasta el tercer día; y el edema en subserosa fue leve el primer día y más evidente el segundo y tercer día. 


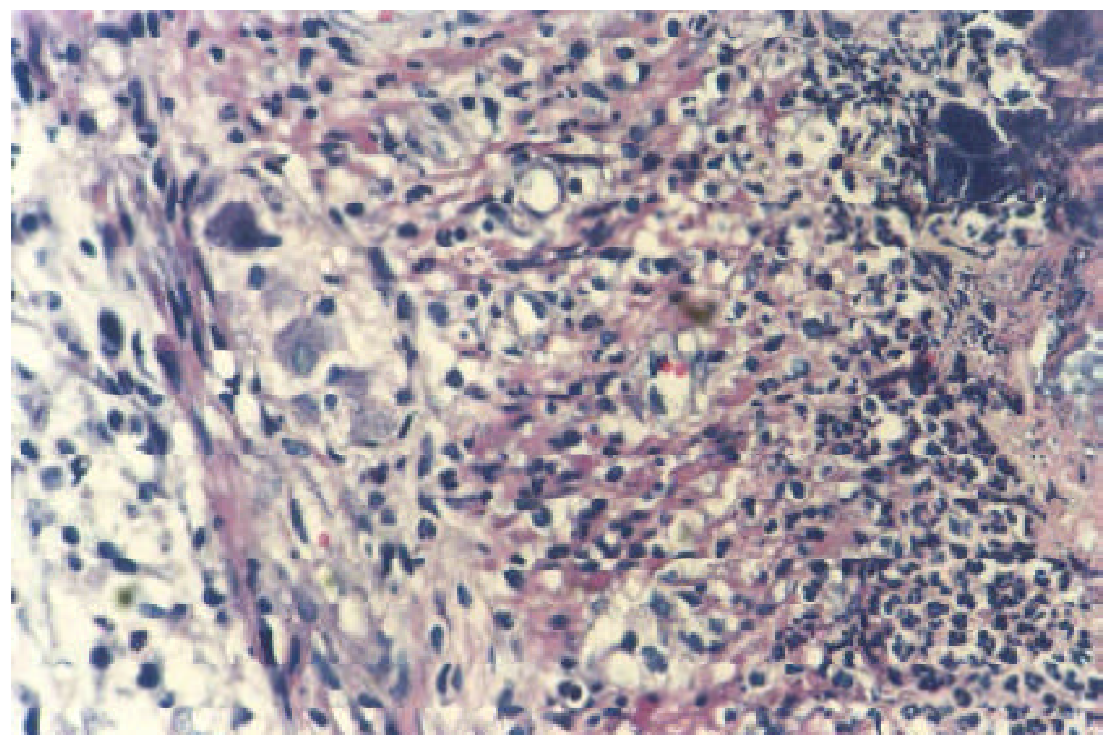

Figura 1. Se observa dilatación de la pared intestinal, hiperemia y múltiples úlceras circulares y longitudinales, a las 72 horas postadministración de indometacina (15 mg/kg p.v)

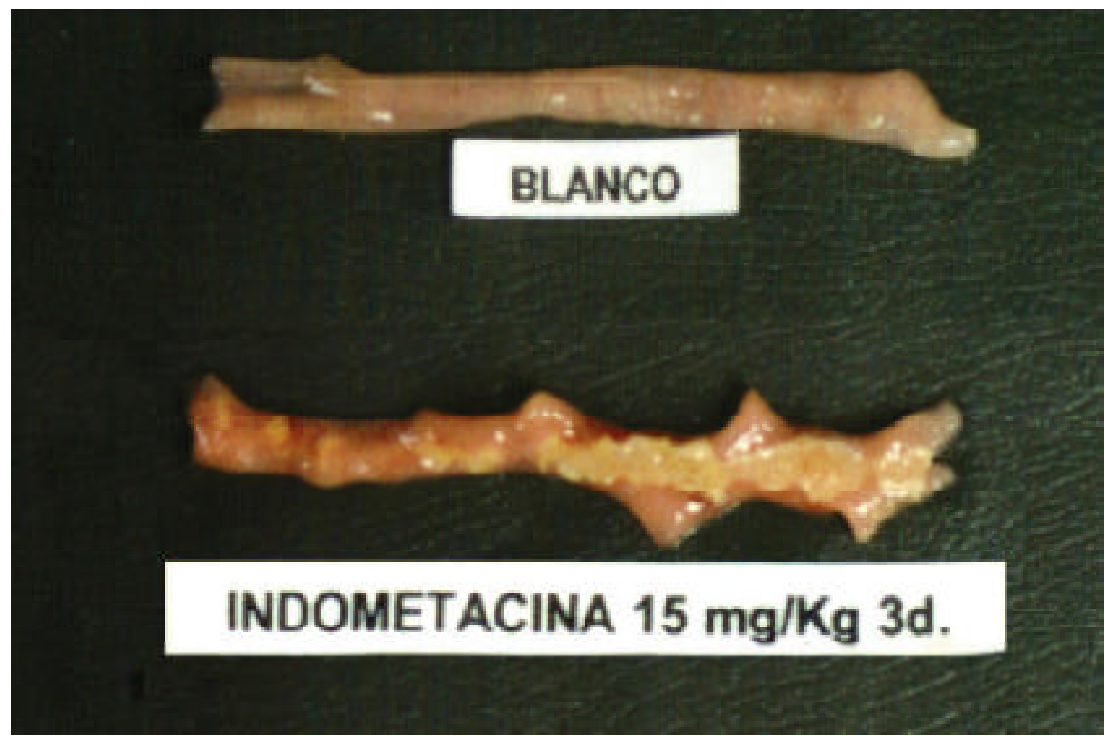

Figura 2. Se observa la presencia de fibrina y bacterias a las 72 horas postadministración de indometacina (15 mg/kg p.v). El exudado inflamatorio es predominantemente neutrofílico, la necrosis de la capa muscular es severa, y hay presencia de fibroblastos con neoformación de vasos. También se observa vacuolización y degeneración del plexo mientérico, inflamación severa de la serosa con un leve infiltrado linfocitario. $\mathrm{HE}, 25 \mathrm{X}$

No se encontró diferencia a nivel macroscópico entre los grupos de ratas sacrificadas el primer, segundo y tercer día ( $p>0.05)$. A nivel microscópico se comprobó que existió diferencia entre lotes de tratamien- to ( $\mathrm{p}<0.05$, Cuadro 2). Estadísticamente se demostró que las lesiones encontradas en los lotes 3 y 4 fueron similares, pero diferentes de las halladas en el lote 2 . Se encontró que a nivel microscópico existe una correlación 
Cuadro 1. Grado de lesión macroscópica en el yeyuno de ratas tratadas con indometacina y sacrificadas al primer, segundo y tercer día post inyección, usando la escala de Yamada et al. (1993)

\begin{tabular}{lccc}
\hline & \multicolumn{3}{c}{ Número de animales afectados ${ }^{1}$} \\
\cline { 2 - 4 } Grado & Día 1 & Día 2 & Día 3 \\
\hline Cero & 2 & 1 & 2 \\
Uno & 2 & 1 & 1 \\
Dos & 0 & 0 & 0 \\
Tres & 0 & 0 & 0 \\
Cuatro & 1 & 2 & 2 \\
Cinco & 5 & 6 & 5 \\
\hline
\end{tabular}

${ }^{1} 10$ animales por día de sacrificio

Cuadro 2. Grado de lesión microscópica en el yeyuno de ratas tratadas con indometacina, y sacrificadas al primer, segundo y tercer día post inyección, usando la clasificación de Slauson y Cooper (1990)

\begin{tabular}{lccc}
\hline & \multicolumn{3}{c}{ Número de animales afectados ${ }^{1}$} \\
\cline { 2 - 4 } Grado & Día 1 & Día 2 & Día 3 \\
\hline Cero & 2 & 1 & 2 \\
Leve & 3 & 0 & 1 \\
Moderado & 5 & 2 & 1 \\
Severo & 0 & 7 & 6 \\
\hline
\end{tabular}

${ }^{1} 10$ animales por día de sacrificio

positiva entre el grado de lesión (daño) y los días transcurridos, lo que no sucede a nivel macroscópico cuando se relacionan las mismas variables.

\section{Discusión}

En el presente estudio, la indometacina en dosis de $15 \mathrm{mg} / \mathrm{kg}$ de peso vivo no causó mortalidad en ninguno de los grupos tratados, al igual que en otros estudios donde se usó la misma dosis por vía oral. Sin embargo, en otros estudios, la indometacina vía intragástrica, en dosis mayores a 15 y $20 \mathrm{mg} /$ $\mathrm{kg}$, provocó la muerte hasta en un $100 \%$ de ratas machos Simonsen (Bjarnason et al.,
1988; Kent et al., 1969). Por otro lado, Yamada et al. (1993) reportaron un cuadro de inflamación intestinal aguda sin causar mortalidad, similar a lo obtenido en este ensayo, utilizando una dosis de $7.5 \mathrm{mg} / \mathrm{kg}$ de peso vivo en ratas Sprague-Dawley.

Las lesiones encontradas se ubicaron, preferentemente, en el lado mesentérico del yeyuno medio y distal. Se observó que las úlceras decrecen en tamaño, número e intensidad a medida que se acercan a la unión ileocecal, lo que es coincidente con otros reportes (Yamada et al., 1993; Kent et al., 1969; Fang et al., 1977). Las úlceras intestinales encontradas fueron evidentes dentro de las primeras 24 horas después de 
inyectada la indometacina, y fueron más severas, penetrantes y de mayor longitud, a las 48 horas (Cuadro 1), tal y como fuera explicado por otros autores (Kent et al., 1969; Yamada et al., 1993).

En la evaluación microscópica se observó que el máximo daño ocurrió en el segundo día y se mantuvo hasta el tercer día sin presentar mayores variaciones (Cuadro 2), a diferencia de lo encontrado por Yamada et al. (1993) quienes encuentran el mayor daño al tercer día. Esta diferencia posiblemente se debe a factores tales como la dosis empleada, raza del animal y el medio ambiente donde se desarrolló el experimento.

La presencia de linfocitos ocurrió desde el primer día y los neutrófilos a partir del segundo día, paralelo a la presentación de bacterias, que se encontraron en mayor cantidad a partir del segundo día. Es probable que la invasión microbiana de la mucosa sea el principal factor quimiotáctico (Bjarnason et al., 1993). En la mayoría de los casos de inflamación aguda, los neutrófilos predominan dentro de las primeras 6 a 24 horas, donde se desintegran y desaparecen en 24 a 48 horas (Robbins, 1992), para posteriormente hacerse presentes los linfocitos; sin embargo, en el presente estudio el predominio de linfocitos ocurrió dentro de las primeras 24 horas y a continuación predominaron los neutrófilos, situación similar a la reportada por Yamada et al. (1993).

Estos datos sugieren que los neutrófilos no son los agentes iniciales de la inflamación, aunque es posible que su intervención pueda agravar el cuadro. Además, en este ensayo se apreció una relación directa entre la presencia de neutrófilos y el daño intestinal, que a partir del segundo día se presentan con mayor intensidad; esto a su vez podría estar relacionado con la liberación de metabolitos reactivos de oxígeno procedentes de los neutrófilos tales como el anión superóxido y el radical hidroxilo, cuya presencia en estados de inflamación aguda y crónica del intes- tino delgado han llevado a admitir el protagonismo de dichos radicales en las patologías intestinales (Miura et al., 1991; Salas et al., 1999).

Los factores de perpetuidad de la enteropatía inducida por indometacina parecen ser las bacterias debido a su mecanismo de acción sobre el intestino (Yamada et al. 1993), toda vez que en este estudio se encontró una correlación entre daño intestinal y el número de bacterias.

\section{Conclusiones}

? Una inyección con dosis subletal de indometacina a $15 \mathrm{mg} / \mathrm{kg}$ de peso vivo induce una inflamación aguda en el intestino delgado medio.

? El cuadro inflamatorio de la enteritis es evidente dentro de las primeras 24 horas de aplicada la inyección, siendo los linfocitos los indicadores celulares principales.

? Las lesiones intestinales se manifiestan con mayor intensidad en el segundo día y se mantienen hasta el tercer día sin presentar variación, teniendo como indicador celular inflamatorio principal a los neutrófilos.

\section{Limeratura Citada}

1. Bjarnason, I.; P. Smethurst; A. Levi; A. Price. 1988. Indomethacin induced chronic small intestinal ulceration in the rat. Gastroenterology 94: A37 (Abstract).

2. Bjarnason, I.; J. Hayllar; A. Macpherson; A. Russell. 1993. Side effects of nonsteroidal anti-inflammatory drugs on the small and large intestine in humans. Gastroenterology 104: 1832-1847.

3. Fang, W.; A. Broughton; E. Jacobson. 1977. Indomethacin-induced intestinal inflammation. Digestive Diseases 22: 749-760. 
4. Goodman, G.; T. Rall; A. Nies; P. Taylor. 1991. Las bases farmacológicas de la terapéutica. $8^{a}$ ed. p 643-645. Ed. Médica Panamericana. Buenos Aires, Argentina.

5. Kent, T.; R. Cardelli; F. Stamier. 1969. Small intestinal ulcers and intestinal flora in rats given indomethacin. Am. J. Pathol. 54: 237-249.

6. Miura, S.; M. Suematsu; S. Tanaka; H. Nagata; S. Houzawa; M. Suzuki; I. Kurose; H. Serizawa; M. Tsuchiya. 1991. Microcirculatory disturbance in indomethacin-induced intestinal ulcer. Am. J. Phisiology 261: G213-G219.

7. Reuter, B.; M. Davies; J. Wallace. 1997. Nonsteroidal anti-inflammatory drug enteropathy in rats: role of permeability, bacteria and enterohepatic circulation. Gastroenterology 112: 109111.

8. Robbins, C. 1992. Patología estructural y funcional. $4^{\mathrm{a}}$ ed. p 89-92. Ed. Interamericana-McGraw Hill. España.

9. Salas, A.; J. Panés; J. Piqué. 1999. Estrés oxidativo y daño gastrointestinal. Rev. Gastroenterología y Hepatología 22: 309-317.

10.Slauson, D.; B. Cooper. 1990. Mechanisms of disease. $2^{\text {nd }}$ ed. p 63-65. Williams \& Wilkins. USA.

11. Yamada, T.; E. Deitch; R. Specian; M. Perry; R. Sartor; M. Grisham. 1993. Mechanism of acute and chronic intestinal inflammation induced by indomethacin. Inflammation 17: 641-662. 